\title{
Mammary gland metabolite utilization in response to exogenous glucose or long-chain fatty acids at low and high metabolizable protein levels
}

\author{
K. Nichols, ${ }^{1,2 *}$ A. Bannink, ${ }^{2}$ J. Doelman, ${ }^{3}$ and J. Dijkstra ${ }^{1}$ \\ ${ }^{1}$ Animal Nutrition Group, Wageningen University and Research, PO Box 338, 6700 AH Wageningen, the Netherlands \\ ${ }^{2}$ Wageningen Livestock Research, Wageningen University and Research, PO Box 338, $6700 \mathrm{AH}$ Wageningen, the Netherlands \\ ${ }^{3}$ Trouw Nutrition R\&D, PO Box 220, 5830 AE Boxmeer, the Netherlands
}

\section{ABSTRACT}

We investigated mammary gland metabolism in lactating dairy cattle in response to energy from glucogenic (glucose; GG) or lipogenic (palm olein; LG) substrates at low (LMP) and high (HMP) metabolizable protein levels. According to a $6 \times 6$ Latin square design, 6 rumen-fistulated second-lactation Holstein-Friesian dairy cows ( $97 \pm 13 \mathrm{~d}$ in milk) were abomasally infused with saline (LMP-C); isoenergetic infusions (digestible energy basis) of $1,319 \mathrm{~g} / \mathrm{d}$ glucose (LMP-GG), 676 $\mathrm{g} / \mathrm{d}$ palm olein (LMP-LG), or $844 \mathrm{~g} / \mathrm{d}$ essential AA (EAA; HMP-C); or isoenergetic infusions of $1,319 \mathrm{~g} / \mathrm{d}$ glucose $+844 \mathrm{~g} / \mathrm{d}$ EAA (HMP-GG) or $676 \mathrm{~g} / \mathrm{d}$ palm olein $+844 \mathrm{~g} / \mathrm{d}$ EAA (HMP-LG). Each experimental period consisted of $5 \mathrm{~d}$ of continuous infusion followed by $2 \mathrm{~d}$ of rest. A total mixed ration ( $42 \%$ corn silage, $31 \%$ grass silage, and $27 \%$ concentrate on a dry matter basis) formulated to meet 100 and $83 \%$ of net energy and metabolizable protein requirements, respectively, was fed at $90 \%$ of ad libitum intake by individual cow. Arterial and venous blood samples were collected on d 5 of each period. Infusing GG or LG at the HMP level did not affect milk yield or composition differently than at the LMP level. Neither GG nor LG infusion stimulated milk protein or lactose yield, but fat yield tended to decrease with GG and tended to increase with LG. Infusion of GG increased arterial plasma concentrations of glucose and insulin and decreased concentrations of $\beta$-hydroxybutyrate (BHB), nonesterified fatty acids, long-chain fatty acids (LCFA), total AA, EAA, and group 2 AA. Infusion of LG increased arterial triacylglycerides (TAG) and LCFA but did not affect EAA concentrations. Compared with the LMP level, the HMP level increased arterial concentrations of BHB, urea, and all EAA groups and decreased the concentration of total non-EAA. Mammary plasma

Received January 11, 2019.

Accepted April 8, 2019.

*Corresponding author: kelly.nichols@wur.nl flow increased with GG and was not affected by LG or protein level. Uptake and clearance of total EAA and group $2 \mathrm{AA}$ were affected or tended to be affected by $\mathrm{GG} \times \mathrm{AA}$ interactions, with their uptakes being lower and their clearances higher with GG, but only at the LMP level. Infusion of LG did not affect uptake or clearance of any AA group. The HMP level increased uptake and decreased clearance of all EAA groups and decreased non-EAA uptake. Infusion of GG tended to increase mammary glucose uptake, and tended to decrease BHB uptake only at the LMP level. Infusion of LG increased mammary uptake of TAG and LCFA and increased or tended to increase clearance of TAG and LCFA. We suspect GG increased mammary plasma flow to maintain intramammary energy and AA balance and stimulated lipogenesis in adipose, accounting for depressed arterial BHB and group 2 AA concentrations. Mammary glucose uptake did not cover estimated requirements for lactose and fat synthesis at the HMP level, except during HMP-GG infusion. Results of this study illustrate flexibility in mammary metabolite utilization when absorptive supply of glucogenic, lipogenic, and aminogenic substrate is increased. Key words: glucogenic, lipogenic, mammary gland, essential amino acid, milk synthesis

\section{INTRODUCTION}

Characterizing the effect of macronutrient supply on mammary gland metabolism of lactating dairy cows is important to achieve efficient and sustainable nutrient transfer from feed into milk components. Lactating mammary glands regulate local blood flow and transmembrane transport to extract substrates for milk component synthesis and to balance cellular ATP requirements in the presence of a deficiency or excess of energy metabolites (Cant et al., 2003). Glucogenic substrates in dairy diets are important to lactating ruminant metabolism because mammary glucose use is high, but net glucose absorption from the gastrointestinal tract is low (Huntington et al., 2006). Hyperinsulinemia caused by 
elevated circulating glucose concentrations or insulin infusion stimulates milk protein synthesis (Mackle et al., 2000; Bequette et al., 2001; Rulquin et al., 2004); however, this endocrine response may also be responsible for reduced arterial concentrations of EAA, acetate, BHB, and nonesterified fatty acids (NEFA) in mid- to late-lactation cows when extramammary peripheral tissues are insulin sensitive (Mackle et al., 1999; Curtis et al., 2018). On the other hand, lipogenic substrates improve the transfer of dietary energy into milk energy (van Knegsel et al., 2007; Boerman et al., 2015), but their metabolism does not provide a net supply of glucose. Lipogenic diets created through provision of high-fiber forages, supplementation of rumen-inert long-chain fatty acids (LCFA), or both may stimulate total milk, protein, and lactose production to the same or to a greater degree relative to glucogenic diets in early- and mid-lactation cows (van Knegsel et al., 2007; Hammon et al., 2008; Boerman et al., 2015), but lipogenic diets do not initiate the same insulin-stimulated endocrine cascade as glucogenic or aminogenic diets (van Hoeij et al., 2017; Nichols et al., 2019a).

Postruminal fat supplementation has received less attention relative to that of glucose with regard to its effect on mammary metabolite utilization. Early work described mammary metabolite use in response to largely unsaturated fat sources (Casper and Schingoethe, 1989; Cant et al., 1993a,b). Cant et al. (1993a) replaced a portion of cereal grains in the diet with a mix of saturated and unsaturated fats and observed increased mammary uptake of triacylglycerides (TAG) and output of LCFA in milk, higher lactose yield, and increased mammary glucose utilization for lactose. In the same study, AA arteriovenous (AV) differences increased but mammary blood flow decreased on high-fat diets (Cant et al., 1993b). Arieli et al. (2001) observed no difference in mammary extraction efficiency of AA with abomasal infusion of corn oil. Recently, Nichols et al. (2019a) reported that supplementing rumen-inert saturated fat did not affect mammary AA metabolism.

In the same experiment as described in the current work (Nichols et al., 2019b), we found that at low and high MP levels, arterial insulin concentration in midlactation cows was increased by abomasal infusion of glucose but was not affected by infusion of palm olein (major fatty acid [FA] constituents are palmitic, oleic, and linoleic acid). Furthermore, glucose infusion increased energy retention, reduced milk energy output, and improved milk $\mathrm{N}$ efficiency; palm olein infusion increased milk energy output and had no effect on energy retention and milk $\mathrm{N}$ efficiency; and EAA infusion increased milk energy output without affecting energy retention and decreased milk $\mathrm{N}$ efficiency. In the current study we measured mammary gland metabolite utilization when glucose or palm olein were supplied at low and high MP levels. We hypothesized that glucose infusion would stimulate mammary gland mechanisms to sequester AA to a greater extent than palm olein. We expected the high MP level, achieved through EAA infusion, to increase mammary gland uptake of EAA as well as increase intramammary AA catabolism.

\section{MATERIALS AND METHODS}

\section{Experimental Design}

All experimental procedures were conducted under the Dutch Law on Animal Experiments in accordance with EU Directive 2010/63. The experimental design, animal housing, ration composition and preparation, and feed chemical analyses have been described in detail by Nichols et al. (2019b). Briefly, effects of energy from glucogenic $(\mathbf{G G})$ or lipogenic $(\mathbf{L G})$ substrates at low (LMP) and high (HMP) MP levels were tested according to a $3 \times 2$ factorial arrangement (absence or presence of supplemented energy from GG or LG $\times$ MP level) using 6 rumen-fistulated second-lactation Holstein-Friesian dairy cows (97 \pm 13 DIM) randomly assigned to a $6 \times 6$ Latin square design, in which each experimental period consisted of $5 \mathrm{~d}$ of continuous abomasal infusion followed by $2 \mathrm{~d}$ of no infusion. Cows were housed individually in identical climate respiration chambers (CRC; described in detail by van Gastelen et al. 2015) and were allowed $5 \mathrm{~d}$ of adaptation to the CRC environment before the first experimental period began. Cows were fed a TMR $(14 \% \mathrm{CP})$ consisting of $42 \%$ corn silage, $31 \%$ grass silage, and $27 \%$ concentrate on a DM basis that was formulated to meet 100 and $83 \%$ of $\mathrm{NE}_{\mathrm{L}}$ and $\mathrm{MP}$ requirements (Centraal Veevoederbureau, 2008), respectively, for cows consuming 20 $\mathrm{kg} \mathrm{DM} / \mathrm{d}$ and producing $30 \mathrm{~kg} / \mathrm{d}$ of milk containing $40 \mathrm{~g} / \mathrm{kg}$ fat and $34 \mathrm{~g} / \mathrm{kg}$ protein. Daily feed intake for individual cows was restricted to $90 \%$ of individual daily ad libitum intake determined during a 10-d diet adaptation period in tie stalls before cows entered the CRC. Fresh feed was allocated twice daily during the entire experiment, with the exception of a 34 -h window over d 4 and 5 of each period (from $0530 \mathrm{~h}$ on d 4 until $1530 \mathrm{~h}$ on $\mathrm{d} 5$ ), during which an automated feeding system dispensed equal portions of feed every $2 \mathrm{~h}$ to promote metabolic steady-state conditions in preparation for the blood sampling protocol described below.

Infusion lines were placed in the abomasum via the rumen cannula $7 \mathrm{~d}$ before the first experimental period and were checked daily for patency and position. Abomasal infusion treatments were (1) $0.9 \%$ saline (LMP-C; $90 \% \mathrm{NE}_{\mathrm{L}}, 75 \% \mathrm{MP}$ ), (2) 1,319 g/d glucose (LMP-GG; $100 \% \mathrm{NE}_{\mathrm{L}}, 75 \% \mathrm{MP}$ ), (3) $676 \mathrm{~g} / \mathrm{d}$ palm 
olein (LMP-LG; 100\% NE, $75 \%$ MP), (4) 844 g/d EAA (HMP-C; $100 \% \mathrm{NE}_{\mathrm{L}}, 120 \% \mathrm{MP}$ ), (5) 1,319 g/d glucose $+844 \mathrm{~g} / \mathrm{d}$ EAA (HMP-GG; $110 \% \mathrm{NE}_{\mathrm{L}}, 120 \% \mathrm{MP}$ ), and (6) $676 \mathrm{~g} / \mathrm{d}$ palm olein $+844 \mathrm{~g} / \mathrm{d}$ EAA (HMP-LG; $110 \% \mathrm{NE}_{\mathrm{L}}, 120 \% \mathrm{MP}$ ), in which $\mathrm{MP}$ and $\mathrm{NE}_{\mathrm{L}}$ reflect the proportion of requirements met by the restricted feeding level of the diet plus the infusate. Treatment solutions were administered in 10-L batches that were replenished daily and infused continuously via multichannel peristaltic pumps at a rate of $6.95 \mathrm{~mL} / \mathrm{min}$ to facilitate 120 -h of continuous infusion. Daily infusion dosages (g/d) of LMP-GG, LMP-LG, and HMP-C were designed to be isoenergetic based on the gross energy content of the EAA infusion, which was calculated to be $24.3 \mathrm{MJ} / \mathrm{kg}$ based on the heat of combustion of individual EAA in the infusate and assuming digestibility of palm olein, EAA, and glucose to be $80 \%, 100 \%$, and $100 \%$, respectively. The EAA infusions delivered EAA in the same profile and amount as found in $1.5 \mathrm{~kg}$ of casein according to Metcalf et al. (1996). Composition of the EAA mixture and palm olein FA composition are described by Nichols et al. (2019b).

\section{Milk and Blood Collection and Analysis}

Cows were milked twice daily at 0530 and $1530 \mathrm{~h}$. Milk was collected, weighed, and sampled separately at each milking. Samples were stored at $4^{\circ} \mathrm{C}$ and analyzed within $4 \mathrm{~d}$ for protein, fat, lactose, and urea by mid-infrared spectroscopy (ISO 9622; ISO, 2013; VVB, Doetinchem, the Netherlands). At 0730, 0930, 1130, 1330, and $1530 \mathrm{~h}$ on d 5 of infusion, blood samples were collected into 10-mL sodium heparin and potassium EDTA Vacutainers (Becton Dickinson, Rutherford, NJ) from the coccygeal vessels and from the subcutaneous abdominal vein of each cow. Arteriovenous differences across the tail are assumed to be negligible and thus samples from the coccygeal vessels are representative of mammary arterial supply (Emery et al., 1965). Samples were collected from the left and right subcutaneous abdominal veins, alternating at each time point, to account for differences between sides. Collection tubes were immediately placed in ice and centrifuged at 3,000 $\times g$ for 15 min at room temperature. Plasma from each time point was collected and stored at $-80^{\circ} \mathrm{C}$ pending analysis of AA, peptides, and AA metabolites. Plasma for analysis of other metabolites and insulin was pooled over sampling time points by cow and period and stored at $-20^{\circ} \mathrm{C}$ until analysis. Plasma AA, peptides, and AA metabolite concentrations were determined using an ultra-performance liquid chromatography-mass spectrometry system (Waters Acquity Ultra Performance LC system, Waters Corp., Milford, MA) as described by Haque et al. (2012). Plasma concentrations of glucose,
BHB, NEFA, TAG, urea, and insulin were analyzed by the Veterinary Diagnostic Laboratory (Utrecht University, the Netherlands) as described by van Knegsel et al. (2007).

\section{Calculations and Statistical Analysis}

Plasma concentrations of AA, peptides, and AA metabolites were averaged over the 5 sampling times. Milk CP was assumed to consist of $94.5 \%$ true protein (DePeters and Ferguson, 1992). All following calculations were based on this estimate of true protein yield. Long-chain fatty acid concentrations were calculated on a molar basis as $3 \times$ TAG + NEFA. Although it is a semi-essential AA for dairy cattle, Arg has been included in all calculations of total EAA. Mammary plasma flow (MPF) across the whole udder was estimated according to the Fick principle using Phe and Tyr as internal markers (Cant et al., 1993b), where $\operatorname{MPF}(\mathrm{L} / \mathrm{h})=[$ milk Phe + Tyr output $(\mu \mathrm{mol} / \mathrm{h})] /[\mathrm{AV}$ Phe + Tyr difference $(\mu \mathrm{mol} / \mathrm{L})]$, with an allowance for $3.37 \%$ contribution of blood-derived proteins to milk Phe + Tyr (Lapierre et al., 2012). Milk output of Phe + Tyr was estimated from the afternoon milk protein yield of d 5, corresponding to the blood samples taken that day, using mean Phe and Tyr contents reported by Mepham (1987) and Lapierre et al. (2012). Uptakes $(\mathrm{mmol} / \mathrm{h})$ of metabolites across the mammary glands were calculated as the product of their plasma AV differences and MPF. Positive uptakes indicate a net removal from plasma, whereas negative values indicate net release from the mammary glands. Mammary metabolite clearances were calculated from the model of Hanigan et al. (1998), where clearance $(\mathrm{L} / \mathrm{h})=(\mathrm{AV}$ difference $\times \mathrm{MPF}) /$ venous concentration. Mean milk protein AA composition reported by Mepham (1987) and Lapierre et al. (2012) was used to calculate AA uptake to output ratios (U:O). Mammary gland balance for glucose and LCFA were calculated according to estimations of Dijkstra et al. (1996) for glucose and LCFA, using milk protein, lactose, and fat yield from the afternoon milking on d 5 of infusion. The molecular weight of $\mathrm{FA} \geq 16 \mathrm{C}$ in blood was calculated according to the molecular weight of $\geq 16 \mathrm{C} \mathrm{FA}$ in milk (Nichols et al., 2019b), assuming that 50\% of milk C16 originated from $\mathrm{C} 16 \mathrm{FA}$ in blood sequestered as preformed FA, and that $50 \%$ of milk C16 was synthesized de novo.

Variances in milk and milk component production, plasma constituent concentrations and AV differences, MPF, mammary metabolite uptakes and clearances, mammary metabolite $\mathrm{U}: \mathrm{O}$, and mammary metabolite balances were analyzed using the MIXED procedure of SAS (SAS Institute Inc., Cary, NC). The model contained main and interaction effects of infusion treat- 
ment factors (GG, LG, and AA) and period as fixed effects and cow as a random effect. We observed no carryover effects between periods, assessed by testing for an effect of the previous treatment in the ANOVA. Differences were considered significant at $P \leq 0.05$ and tendencies were acknowledged at $0.05<P \leq 0.10$. Multiple comparisons between treatment means were made using the Tukey-Kramer method when GG $\times$ AA or $\mathrm{LG} \times \mathrm{AA}$ interactions were detected at $P \leq 0.10$.

\section{RESULTS}

\section{Milk Production}

Daily lactation performance and DMI have been presented by Nichols et al. (2019b). The present paper reports milk production expressed on an hourly basis from the afternoon milking on d 5 of infusion (Table 1). Infusing GG or LG at the HMP level did not affect milk production or composition differently than at the LMP level (no GG $\times$ AA or $\mathrm{LG} \times \mathrm{AA}$ interactions; $P>0.10$ ). Yields of milk, protein, and lactose were unaffected by GG and LG $(P>0.23)$ and increased at the HMP level $(P<0.01)$. The HMP level increased milk protein content $(P<0.01)$ and decreased lactose content $(P<0.01)$. Milk fat yield tended to decrease in response to GG $(P=0.10)$, tended to increase in response to LG $(P=0.09)$, and increased at the HMP level $(P<0.01)$. Milk fat content tended to decrease in response to GG $(P=0.06)$ and increased in response to LG $(P=0.02)$. Milk urea content tended to decrease in response to GG $(P=0.06)$ and increased at the HMP level $(P=0.01)$.

\section{Arterial Metabolite and Insulin Concentrations}

Irrespective of MP level, arterial plasma concentration of glucose and insulin increased in response to GG $(P \leq 0.04$; Table 2$)$ and concentration of BHB, NEFA, and LCFA decreased $(P \leq 0.03)$. Plasma urea tended to be affected by a GG $\times$ AA interaction, whereby its concentration decreased with GG but only at the HMP level $(P=0.08)$. Regardless of MP level, arterial plasma concentration of total EAA, group $2 \mathrm{AA}$, and branched-chain AA (BCAA; $P<0.01)$ decreased in response to GG. A GG $\times$ AA interaction affected Leu concentration $(P=0.05)$, which decreased with GG but only at the HMP level. Infusion of GG decreased Arg, Ile, Lys, and Val concentrations $(P<0.01)$, regardless of MP level. A GG $\times$ AA interaction affected Ala, Asp, and Glu $(P \leq 0.04)$, whereby GG infusion decreased Ala concentration at the LMP level, and GG infusion resulted in numerically lower Asp and Glu at the LMP level compared with the HMP level. Irrespec-

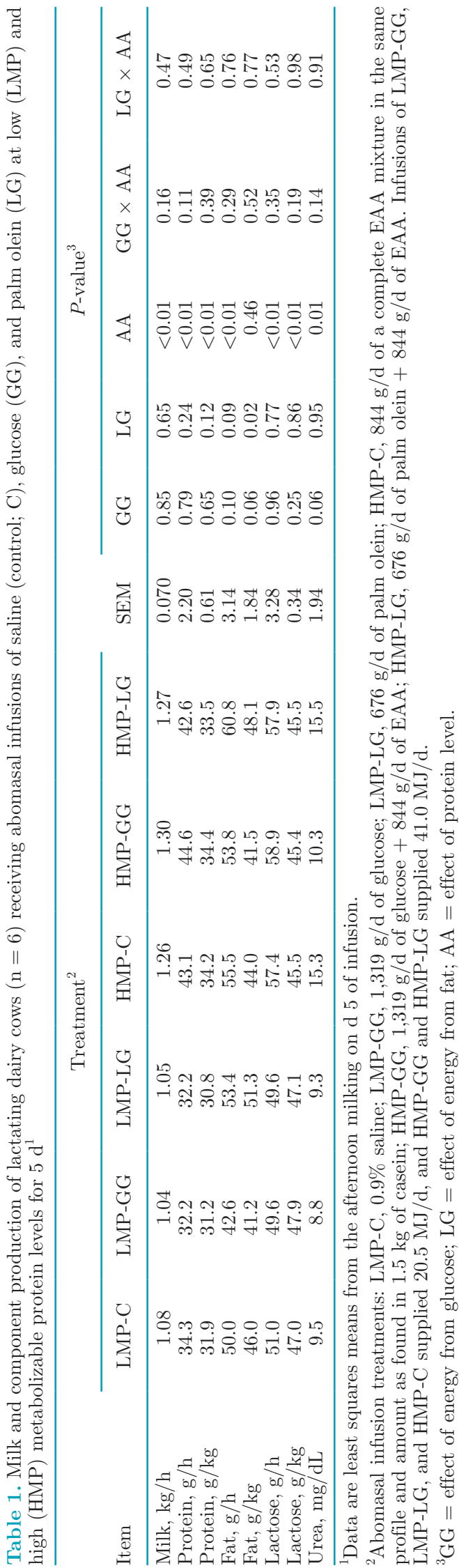

Journal of Dairy Science Vol. 102 No. 8, 2019 
tive of MP level, infusion of GG increased Gly and Ser $(P \leq 0.01)$, decreased Orn $(P<0.01)$, and tended to decrease Cit and Pro $(P \leq 0.08)$. Infusion of GG decreased carnosine concentration but only at the LMP level $(\mathrm{GG} \times \mathrm{AA}$ interaction; $P=0.03)$ and tended to decrease concentration of $\alpha$-amino- $n$-butyric acid $(P=$ $0.09)$ and $\alpha$-amino-adipic acid $(P=0.10)$ irrespective of MP level.

Infusion of LG increased arterial plasma concentration of TAG and LCFA $(P<0.01)$ irrespective of MP level. Plasma urea concentration was numerically lower at the LMP level and numerically higher at the HMP level with LG infusion (tendency for $\mathrm{LG} \times \mathrm{AA}$ interaction; $P=0.09$ ). Infusion of LG did not affect plasma concentration of any AA group or any individual EAA $(P>0.39)$. A LG $\times$ AA interaction tended to affect Pro concentration, which decreased only at the HMP level $(P=0.09)$. Infusion of LG tended to decrease concentrations of Asn $(P=0.06)$ and Tyr $(P=0.07)$. Concentration of 1 methyl-histidine was higher with LG infusion at the LMP level compared with the HMP level $(\mathrm{LG} \times \mathrm{AA}$ interaction; $P=0.05)$.

The HMP level increased arterial plasma concentrations of BHB, urea (dependent on GG and LG level), and concentrations of all EAA groups $(P \leq 0.01)$. All individual EAA increased at the HMP level $(P<0.01)$. The HMP level decreased total NEAA concentration $(P$ $<0.01$ ), and individual concentrations of Ala (dependent on GG level), Asn, Gln, Gly, Pro (dependent on LG level), and Ser $(P \leq 0.05)$. The HMP level increased Cit, Orn, and Tyr $(P \leq 0.01)$ and tended to increase Cys $(P=0.08)$. The HMP level increased the concentration of $\alpha$-amino- $n$-butyric acid, $\alpha$-amino-adipic acid, carnosine (dependent on GG level), cystathionine, and phosphoserine $(P \leq 0.01)$, and decreased 1 methylhistidine (dependent on LG level), 3 methyl-histidine, and hydroxyproline $(P \leq 0.04)$.

\section{Mammary Metabolite AV Differences}

Regardless of MP level, GG decreased the AV difference of BHB and TAG $(P<0.01)$ and tended to decrease that of LCFA $(P=0.07$; Table 3$)$. The AV differences of all EAA groups were affected by a $G G \times$ AA interaction, decreasing with GG only at the HMP level $(P \leq 0.05)$. Individually, this interaction affected Met, Phe, Thr, Trp, and Val $(P \leq 0.05)$ and tended to affect His $(P=0.09)$, Ile $(P=0.10)$, and Leu $(P=$ 0.08). Infusion of GG decreased AV differences of Arg and Lys, irrespective of MP level $(P<0.01)$. The AV difference of total NEAA tended to be affected by a GG $\times$ AA interaction, decreasing with GG only at the HMP level $(P=0.06)$. Individually, this interaction affected Cit, Gln, Gly, and Pro $(P \leq 0.05)$ and tended to affect $\operatorname{Ser}(P=0.07)$ and Tyr $(P=0.09)$. The AV difference of Glu was numerically decreased at the LMP level and increased at the HMP level (tendency for GG $\times$ AA interaction; $P=0.06)$. Regardless of MP level, GG decreased the AV differences of Asn and Orn $(P \leq$ $0.02)$.

Regardless of MP level, LG increased the AV difference of TAG and LCFA $(P<0.01)$. Infusion of LG did not affect the AV difference of any AA group or individual AA $(P>0.10)$, except that of His, which tended to decrease $(P=0.07)$. The HMP level increased the AV difference of BHB $(P<0.01)$. The AV differences of all EAA groups increased at the HMP level (all dependent on GG level; $P \leq 0.01$ ). Individually, the AV differences of all EAA except Trp increased at the HMP level $(P \leq 0.03)$, with increases for His, Ile, Leu, Met, Phe, Thr, and Val depending on GG level. The AV differences of Ala and Pro decreased (for Pro dependent on GG level; $P \leq 0.02$ ) and the AV difference of Gly tended to decrease (dependent on GG level; $P=0.07$ ) at the HMP level.

\section{Mammary Plasma Flow and Metabolite Uptake}

Irrespective of MP level, infusion of GG increased MPF $(P=0.02$; Table 4$)$ and tended to increase mammary net glucose uptake $(P=0.07$; Table 4$)$. A GG $\times$ AA interaction tended to affect BHB uptake, which was numerically lower with GG only at the LMP level $(P=0.10)$. A GG $\times$ AA interaction tended to affect uptake of total EAA $(P=0.09)$ and group 2 AA $(P=$ 0.08 ), whereby their uptake was numerically lower at the LMP level and not affected at the HMP level. A GG $\times$ AA interaction affected Arg and Lys $(P \leq 0.03)$ and tended to affect Ile and Leu $(P \leq 0.08)$, whereby their uptake was decreased with GG at the LMP level. Uptake of Trp was higher with GG at the LMP level $(\mathrm{GG} \times \mathrm{AA}$ interaction; $P=0.03)$. Irrespective of MP level, infusion of GG decreased uptake of His and Met $(P=0.05)$. A GG $\times$ AA interaction affected uptake of Glu, Orn, and Tyr, with Glu uptake increasing with GG only at the HMP level $(P=0.02)$, Orn uptake decreasing with GG only at the LMP level $(P=0.04)$, and Tyr uptake being numerically higher with GG at the HMP level $(P=0.03)$ A GG $\times$ AA interaction tended to affect uptake of Cit, which was numerically lower at the HMP level $(P=0.07)$.

Irrespective of MP level, LG infusion increased mammary net uptake of TAG and LCFA $(P<0.01)$ and had no effect on uptake of any AA group or individual AA, except Ser uptake, which tended to increase $(P=$ 0.07). Mammary net uptake of BHB was affected by MP level but only in the presence of GG $(P=0.02)$. The HMP level increased mammary uptake of all EAA 


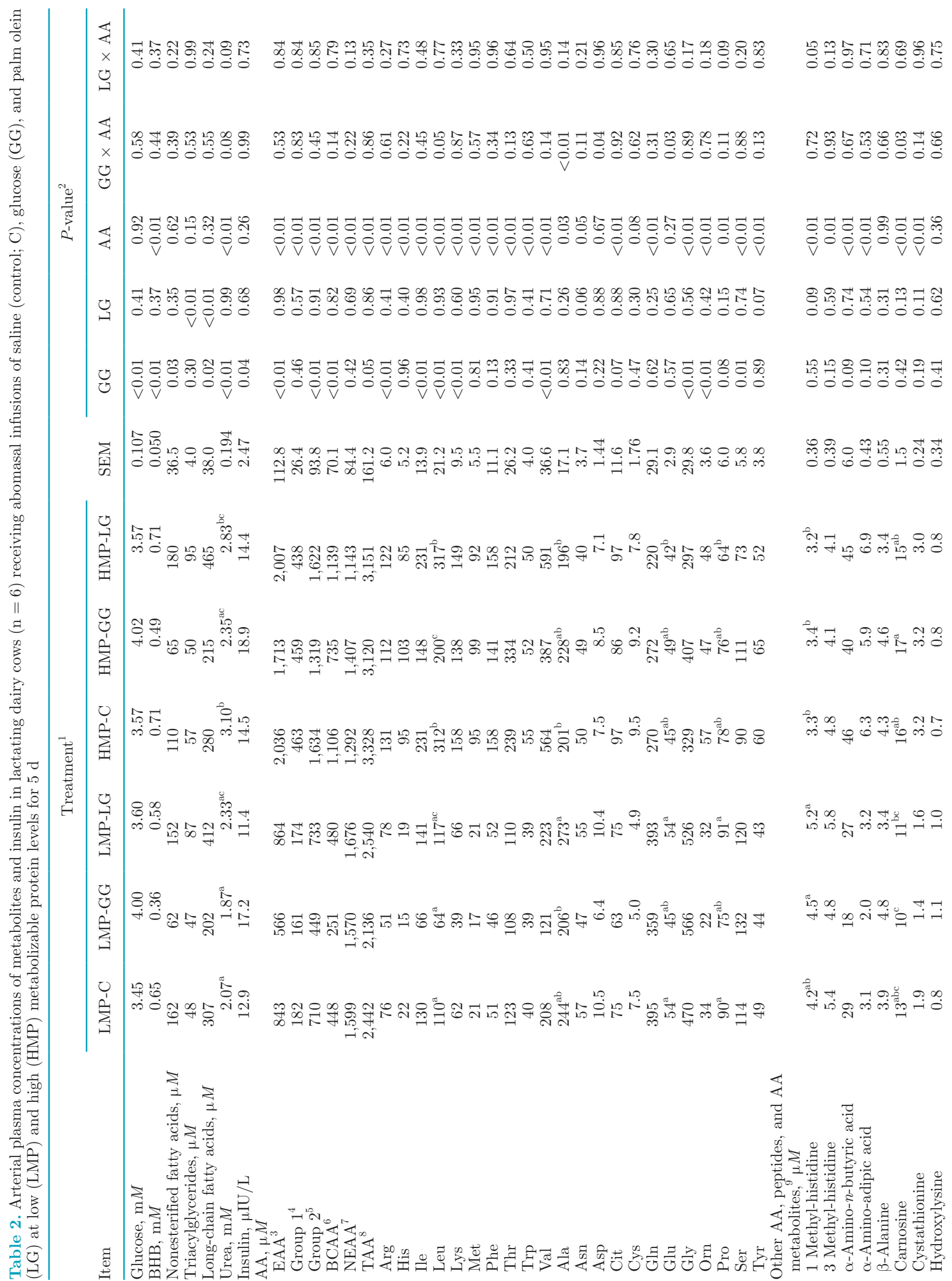


groups $(P<0.01)$. The HMP level increased individual uptake of all EAA $(P<0.01)$, with the exception of Trp, which was unaffected, while uptakes of Arg and Lys were dependent on GG level. Mammary net uptake of total NEAA decreased at the HMP level $(P=0.03)$. Individually, the HMP level increased Tyr uptake $(P=$ 0.01; dependent on GG), tended to increase Asn uptake $(P=0.08)$, and decreased uptake of Ala, Gly, and Pro $(P \leq 0.04)$.

\section{Mammary Metabolite Clearance}

Infusion of GG had no effect on mammary clearance of glucose, BHB, NEFA, TAG, or LCFA, irrespective of MP level $(P \geq 0.11$; Table 5$)$. Total EAA clearance was affected $(P=0.04)$ and group 2 AA clearance tended to be affected $(P=0.10)$ by a $\mathrm{GG} \times \mathrm{AA}$ interaction, with both increasing in response to GG only at the LMP level. Clearance of total BCAA increased in response to GG regardless of MP level $(P<0.01)$. Individually, a $\mathrm{GG} \times \mathrm{AA}$ interaction affected Leu and Trp $(P \leq 0.05)$ and tended to affect Arg and Val $(P$ $\leq 0.08)$, with clearances increasing in response to GG only at the LMP level. Clearance of Ile increased $(P$ $<0.01)$ and clearance of Lys tended to increase $(P=$ 0.06) in response to GG, regardless of MP level. A GG $\times$ AA interaction affected Cit $(P=0.05)$ and tended to affect Cys $(P=0.07)$, with their clearances increasing in response to GG only at the LMP level. Infusion of GG increased Glu clearance regardless of MP level $(P$ $=0.04)$.

Infusion of LG increased clearance of TAG $(P=0.01)$ and tended to increase clearance of LCFA $(P=0.06)$, regardless of MP level. Irrespective of MP level, LG did not affect clearance of any AA group or any individual EAA. A LG $\times$ AA interaction affected Asp $(P=0.04)$ and tended to affect Asn $(P=0.06)$, with clearances increasing with LG only at the HMP level. Clearance of Ser increased in response to LG regardless of MP level $(P<0.01)$. The HMP level tended to increase mammary clearance of BHB $(P=0.10)$. Clearance of all EAA groups decreased at the HMP level $(P<0.01)$. Clearance of total EAA was affected by a $\mathrm{GG} \times \mathrm{AA}$ interaction $(P=0.04)$, decreasing more at the HMP level relative to the LMP level in the presence of GG. Clearances of all individual EAA decreased at the HMP level $(P \leq 0.05)$, except clearances of Trp and Val, which were affected by MP level in the presence of GG $(P \leq 0.07)$, and Arg and Leu, which decreased more at the HMP level relative to the LMP level in the presence of GG $(P \leq 0.08)$. The HMP level increased clearance of Asn (dependent on LG), Gln, and Ser $(P<0.01)$; tended to increase clearance of Asp $(P=0.08$; depen- 
MAMMARY METABOLISM WITH GLUCOSE AND FAT INFUSIONS

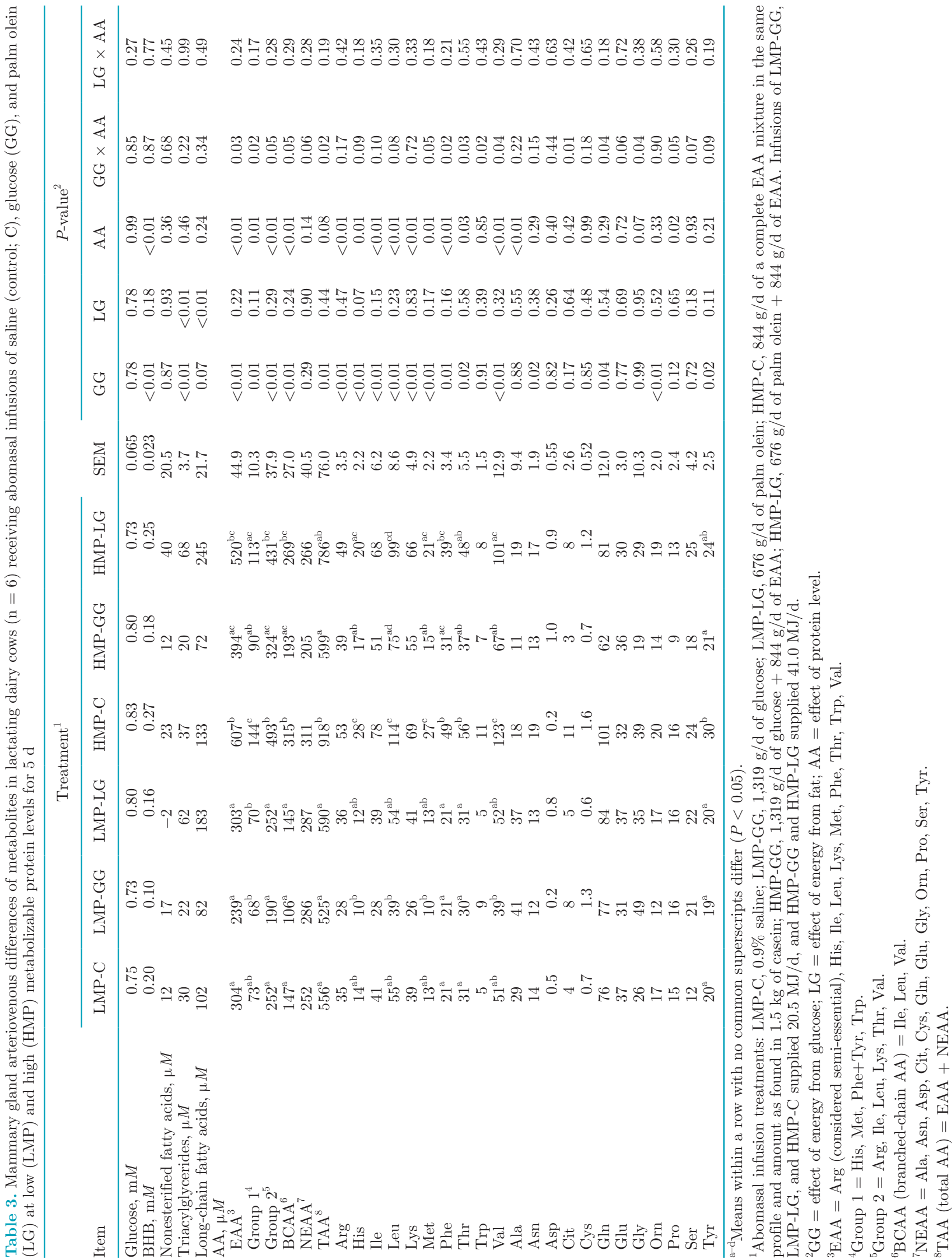


MAMMARY METABOLISM WITH GLUCOSE AND FAT INFUSIONS

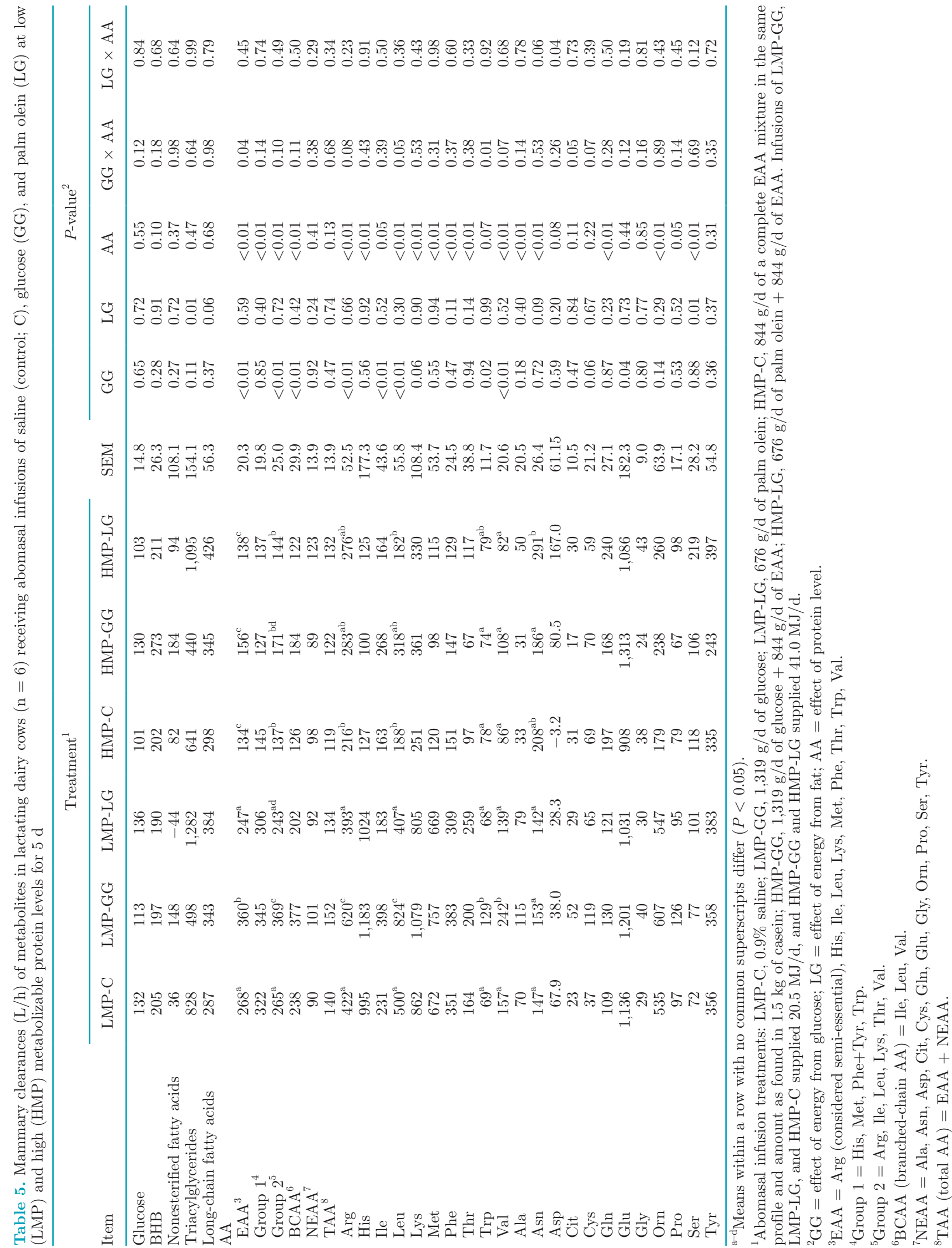


dent on LG); and decreased clearance of Ala, Orn, and Pro $(P \leq 0.05)$.

\section{Mammary AA U:O}

Irrespective of MP level, GG tended to decrease the $\mathrm{U}: \mathrm{O}$ of total BCAA $(P=0.09$; Table 6$)$. A GG $\times$ AA interaction affected U:O of Arg and Lys, which numerically decreased with GG at the LMP level and increased with GG at the HMP level $(P \leq 0.03)$; affected U:O of Trp, which increased with GG but only at the LMP level $(P=0.01)$; and tended to affect $\mathrm{U}: \mathrm{O}$ of Ile, which decreased with GG but only at the LMP level $(P=0.08)$. The $\mathrm{U}: \mathrm{O}$ of His and Met decreased ( $P$ $\leq 0.03)$ and $\mathrm{U}: \mathrm{O}$ of Val tended to decrease $(P=0.08)$ in response to $\mathrm{GG}$, regardless of $\mathrm{MP}$ level. A GG $\times \mathrm{AA}$ interaction tended to affect Glu $(P=0.08)$ and Gly $(P$ $=0.09$ ), with GG numerically increasing $\mathrm{U}: \mathrm{O}$ of Glu at the HMP level and numerically increasing $\mathrm{U}: \mathrm{O}$ of Gly at the LMP level and decreasing it at the HMP level.

Regardless of MP level, infusion of LG had no effect on $\mathrm{U}: \mathrm{O}$ of any AA group or individual AA, except for $\mathrm{U}: \mathrm{O}$ of Ser, which increased $(P=0.04)$. The HMP level increased $\mathrm{U}: \mathrm{O}$ of total EAA, group $2 \mathrm{AA}$, and BCAA $(P<0.01)$. In the presence of $\mathrm{GG}$, the $\mathrm{U}: \mathrm{O}$ of Ile and Lys increased at the HMP level compared with the LMP level $(P \leq 0.02)$. The U:O of Leu, Phe, and Val increased $(P \leq 0.01)$ and $\mathrm{U}: \mathrm{O}$ of His $(P=0.07)$ and Met $(P=0.08)$ tended to increase at the HMP level. In the presence of GG, the U:O of Trp decreased at the HMP level compared with the LMP level $(P=0.03)$. The HMP level decreased the U:O of total NEAA $(P$ $<0.01)$. Individually, $\mathrm{U}: \mathrm{O}$ of all NEAA decreased at the HMP level $(P<0.01)$, except Asn, which tended to decrease $(P=0.07)$, and Asp, Cys, and Ser, which were unaffected $(P>0.10)$.

\section{Mammary Glucose and LCFA Balance}

Lactose output as a proportion of mammary glucose uptake decreased in response to GG regardless of MP level $(P=0.03)$ and increased at the HMP level $(P$ $=0.03$; Table 7$)$. The calculated amount of glucose required for milk fat synthesis tended to decrease in response to $\mathrm{GG}(P=0.10)$ and tended to increase in response to LG $(P=0.09)$. The calculated glucose required for lactose and milk fat synthesis increased at the HMP level $(P \leq 0.01)$. Net glucose uptake by the mammary gland did not cover calculated glucose requirements for lactose and fat synthesis on any treatment, with the exception of LMP-GG. Infusion of GG reduced the deficit $(P=0.03)$, while the HMP level increased it $(P=0.02)$. Output of LCFA in milk decreased in response to GG and increased in response to
LG $(P<0.01)$. Net mammary LCFA uptake did not equilibrate with output in milk on any treatment, but infusion of LG reduced the deficit $(P=0.04)$.

\section{DISCUSSION}

The current results complement previously reported daily lactation performance, milk FA composition, and energy and $\mathrm{N}$ balance from the same study (Nichols et al., 2019b). Notably, GG reduced milk energy output and increased body energy retention, whereas LG increased milk energy output and did not affect body energy retention. Body $\mathrm{N}$ mobilization occurred with LMP-GG but N retention occurred with HMP-GG, and GG improved milk $\mathrm{N}$ efficiency regardless of protein level. Body N retention was positive with LG infusion, and LG had no effect on milk $\mathrm{N}$ efficiency (Nichols et al., 2019b). Considering the milk output and wholebody energy and $\mathrm{N}$ balance responses observed in this experiment, we investigated mammary gland metabolism in response to glucose and palm olein supplied at low and high MP levels in the present work.

\section{Milk Protein Yield and AA Catabolism Increased at the HMP Level}

The objective of EAA infusion in the current study was to create low and high MP levels over which to compare the effects of GG and LG. As expected, the HMP level increased the arterial concentration of total EAA to 2.5 times that of the LMP level and increased milk protein yield $32 \%$, in line with previous reports of postruminal EAA infusions lasting 5 to $14 \mathrm{~d}$ (Doepel and Lapierre, 2010; Doelman et al., 2015; Nichols et al., 2016). In agreement with our hypothesis, mammary net uptake of all EAA groups increased at the HMP level, but MPF was not affected and mammary clearance decreased. Decreased mammary clearance of EAA is consistent with surplus EAA supply for milk protein synthesis. Surplus EAA become available for extramammary metabolism, which is in line with increased body $\mathrm{N}$ retention at the HMP level (Nichols et al., 2019b). The U:O of total group 1 AA (His, Met, Phe+Tyr, Trp) was not affected by MP level, while U:O of group 2 AA (Arg, Ile, Leu, Lys, Val, Thr) and NEAA increased and decreased, respectively, at the HMP level. This dynamic of mammary gland AA utilization during EAA supplementation, whereby group 2 AA mammary uptake and intramammary catabolism increases while NEAA uptake decreases, agrees with the observations of Nichols et al. (2016) during 5-d abomasal infusion of the same EAA profile and dose.

The average U:O of Phe at the HMP level was 1.23, which is relatively greater than the average $\mathrm{U}: \mathrm{O}$ of the 
MAMMARY METABOLISM WITH GLUCOSE AND FAT INFUSIONS
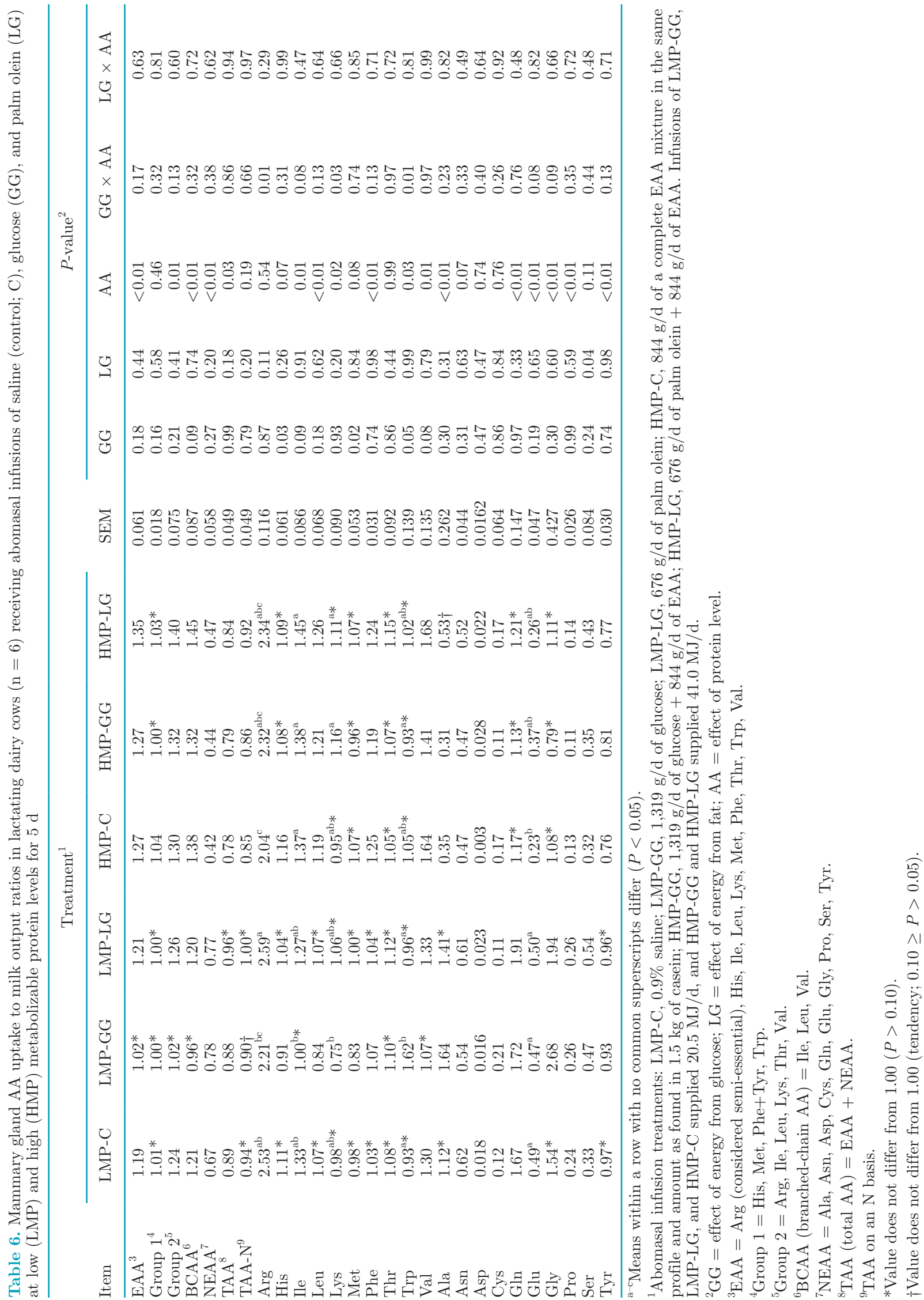


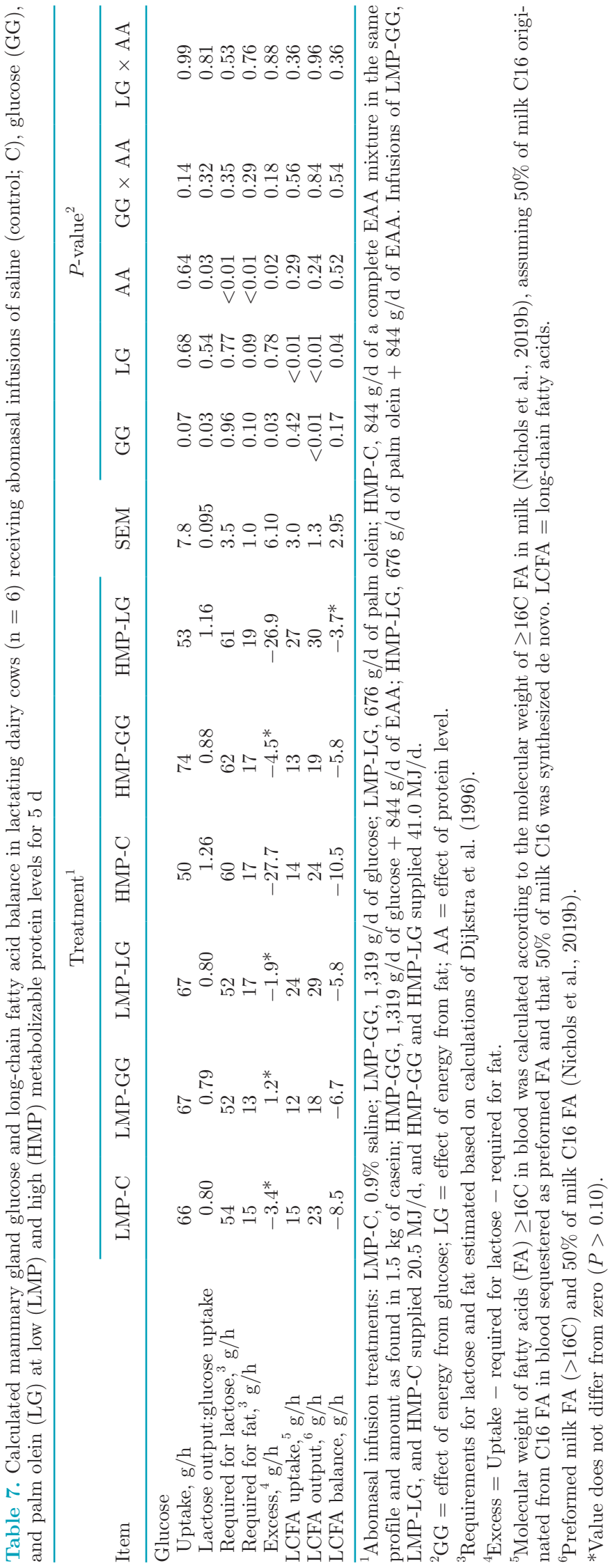

other individual group $1 \mathrm{AA}$ at the HMP level (His, 1.11; Met, 1.03; Trp, 1.00). At the LMP level, average Phe U:O was 1.05 and in line with previous ranges observed from cows fed low (11.8\%) and high (16.5\%) CP contents (Crompton et al., 2014). The individual $\mathrm{U}: \mathrm{O}$ of Tyr decreased from 0.95 on average at the LMP level to 0.78 on average at the HMP level, the latter of which is low compared with the range reported by Crompton et al. (2014). A possible explanation is that the high level of EAA infusion in the current study caused a relative shortage of Tyr and the intramammary hydroxylation of Phe to Tyr increased at the HMP level. If the excess uptake relative to milk output of Phe was converted to Tyr, according to our assumption for the Fick principle, approximately $22 \%$ of milk Tyr would have come from mammary-sequestered Phe. Verbeke et al. (1972) suggested that hydroxylation of Phe to Tyr is influenced by Phe concentration, and Jorgensen and Larson (1968) showed that this conversion is affected by presence or absence of Tyr in mammary cells. Both observations would support a high level of conversion of Phe to Tyr when mammary gland Phe uptake increased $54 \%$ at the HMP level relative to the LMP level. However, the extent to which intramammary Phe contributes to Tyr synthesis is still not well established, and significant amounts of intracellular Tyr may originate from mammary tissue breakdown or may arise not only from plasma free AA but also from mammary uptake of peptides (Lemosquet et al., 2010; Crompton et al., 2014).

The HMP level decreased net U:O of total AA (TAA). Our EAA infusion rate of $844 \mathrm{~g} / \mathrm{d}$ is high relative to others infusing EAA mixtures in a casein profile (Doepel and Lapierre, 2010; Maxin et al., 2013; Doelman et al., 2015). When exogenous EAA supply is high and imbalanced relative to NEAA for casein synthesis and intramammary metabolism increases, net $\mathrm{U}: \mathrm{O}$ might not accurately represent TAA transfer. Although total EAA were extracted by the gland in excess of their requirement, mammary uptake of NEAA was reduced at the HMP level relative to their increased output, resulting in a net $\mathrm{U}: \mathrm{O}$ of TAA of $<1$. When calculated on an $\mathrm{N}$ basis, the $\mathrm{U}: \mathrm{O}$ of TAA is closer to unity, which supports contribution of $\mathrm{N}$ from group 2 AA to $\mathrm{N}$ required for de novo NEAA synthesis (Lapierre et al., 2012). At infusion doses similar to ours, but when casein or mixtures of EAA+NEAA are infused, U:O of TAA are $\geq 1$ (Guinard and Rulquin, 1994; Raggio et al., 2006b; Doepel and Lapierre, 2010). Under the condition of high EAA supply that is also imbalanced relative to NEAA required for casein synthesis, peptide-bound AA may be extracted by the gland to compensate for the deficiency. Evidence of this contribution at low or high protein supplies is equivocal but has been suggested in 
scenarios in which AA supply for milk protein synthesis is lacking (Backwell et al., 1994; Bequette et al., 1999, 2001).

\section{Glucogenic Infusion Reduced Group 2 AA Concentration but Milk Protein Yield Was Maintained}

Mammary plasma flow increased $22 \%$ in response to $1.3 \mathrm{~kg} / \mathrm{d}$ of infused glucose, which agrees with increases in MPF of 24 and $36 \%$ in cows infused for $14 \mathrm{~d}$ with 1 $\mathrm{kg}$ /d duodenal glucose or ruminal propionate (Rulquin et al., 2004; Raggio et al., 2006b). Mammary plasma flow will increase or decrease to maintain intramammary energy balance via $2 \mathrm{C}$ compounds (acetate and BHB; Cant et al., 2003). Glucogenic infusions typically reduce circulating acetate and $\mathrm{BHB}$ concentrations (Rigout et al., 2002; Lemosquet et al., 2009; Curtis et al., 2018), which likely stimulates the concomitantly observed hyperaemia. Arterial BHB concentration decreased $36 \%$ with glucose infusion in the current study, which is in line with this proposed regulation of MPF and in agreement with Curtis et al. (2018) in which arterial concentration of acetate + BHB decreased $31 \%$ and MPF increased $36 \%$ in response to $96-\mathrm{h}$ intravenous glucose infusion. Elevated glucose and insulin concentrations observed in response to GG may have reduced arterial BHB through stimulatory effects on lipogenesis in adipose (Vernon et al., 1985), antiketogenic effects in the liver, and BHB oxidation by peripheral tissues (Ørskov et al., 1999).

Arterial plasma concentrations of all group 2 AA, with the exception of Thr, decreased in response to GG, independent of MP level. Others have reported reduced concentrations of group 2 AA upon postruminal infusion of propionate, starch, and glucose (Raggio et al., 2006a; Rius et al., 2010; Nichols et al., 2016), often with no concomitant increase in their net mammary uptake (Raggio et al., 2006b; Nichols et al., 2016; Curtis et al., 2018). In the current study, a GG $\times$ AA interaction affected mammary uptake of Arg, Lys, Ile (tendency), and Leu (tendency) and tended to affect mammary uptake of total group $2 \mathrm{AA}$, indicating lower uptake of these AA at the LMP level and no effect at the HMP level. Considering that glucose infusion reduced circulating group $2 \mathrm{AA}$, increased $\mathrm{MPF}$, and did not decrease milk protein yield, it follows that efficiency of group 2 AA uptake increased in response to GG. This increase was detected in the mammary clearance parameter for Ile and Lys but was more significant at the LMP level than at the HMP level for Arg, Leu, Val, and total group $2 \mathrm{AA}(\mathrm{GG} \times \mathrm{AA}$ interactions). Group 2 AA are typically extracted by the udder in a greater amount relative to their output in milk, and they are used for de novo synthesis of NEAA and as a supply of glycolytic and tricarboxylic acid cycle intermediates (Mepham, 1987; Lapierre et al., 2012). Validity of inclusion of Thr in this group is equivocal (Lapierre et al., 2012) because its contribution to NEAA and oxidation in the mammary gland may be small (Verbeke et al., 1972). Indeed, its individual U:O in the current study did not differ from 1 on any treatment. Nevertheless, when considered together, total group 2 AA U:O was $>1$ on all treatments except LMP-GG. Milk protein yield did not decrease on LMP-GG relative to LMP-C or LMP-LG; therefore, during glucose infusion at the LMP level, intramammary compensation must have occurred to yield AA-N and carbon required to synthesize NEAA and generate energy. Of the group $2 \mathrm{AA}$, individual $\mathrm{U}: \mathrm{O}$ of Arg remained $>1$ and thus could still contribute AA-N and carbon. The U:O of NEAA was numerically highest on LMP-GG. Of the NEAA, U:O of Ala and Gly increased most (numerically) on LMPGG relative to LMP-C and LMP-LG, possibly to offset lower de novo synthesis of these AA. The U:O of Ala appears to be particularly responsive under conditions of low protein intake (Raggio et al., 2006b; Doepel and Lapierre, 2010; Haque et al., 2015) and during insulin infusion (Bequette et al., 2001). In addition, mammary extraction of circulating peptides may contribute relatively more to milk protein synthesis on LMP-GG (Backwell et al., 1994; Bequette et al., 1999; Lapierre et al., 2012), but they were not quantified in the present AV measurements.

Glucose infusion directed a portion of circulating group 2 AA toward utilization in nonmammary tissues, as evidenced by their lower arterial concentration at low and high MP levels, while mammary uptake of group 2 AA was not increased. Metabolism of BCAA and Lys in ruminants occurs predominantly in nonhepatic tissues (Lapierre et al., 2002), and nonmammary sinks for group 2 AA are oxidative catabolism, skeletal muscle protein synthesis, and adipose TAG synthesis (Brosnan and Brosnan, 2006; Raggio et al., 2006a). Partitioning of group 2 AA toward extramammary peripheral tissues in response to GG agrees with the numerical reduction in urinary $\mathrm{N}$ output and increase in body $\mathrm{N}$ retention reported by Nichols et al. (2019b). Furthermore, decreased plasma urea concentration in response to GG, in particular at the HMP level, is in accordance with overall reduced oxidative catabolism of AA. It also agrees with the observations of Raggio et al. (2006a) showing that whole-body oxidation of Leu was not affected during 14-d propionate infusion and was reduced when propionate and casein were infused together. Arterial concentrations of 1 methylhistidine and 3 methyl-histidine were not affected by GG, indicating that muscle protein degradation was not increased, which is in line with the antiproteolytic 
effect of insulin on muscle (Lobley, 1998). However, GG increased the arterial concentration of Gly, which is released from skeletal muscle at high levels relative to other AA when body protein is mobilized (Doepel et al., 2002). These indicators suggest that turnover in the skeletal muscle pool during glucose infusion could have sequestered some of the group $2 \mathrm{AA}$. Considering the BCAA specifically, recent work suggests a role for adipose tissue in BCAA metabolism in dairy cattle when glucose increases insulin concentration and stimulates lipogenesis (Nichols et al., 2016; Curtis et al., 2018). Taken together, the increase in insulin and decrease in BHB and NEFA concentrations, the reduction in milk fat yield, and the increase in body energy retention (observed by Nichols et al., 2019b) in response to GG suggest contribution to lipogenesis in adipose was a likely sink for BCAA carbon skeletons during glucose infusion.

In summary, regardless of MP level, glucose infusion decreased the arterial concentration of group 2 AA. At the LMP level, glucose infusion resulted in numerically lower mammary net uptake of group $2 \mathrm{AA}$, numerically reduced intramammary group 2 AA catabolism (lower $\mathrm{U}: \mathrm{O})$, and did not affect milk protein yield. During glucose infusion at the HMP level, mammary net uptake of group $2 \mathrm{AA}$ was not affected and milk protein yield was not affected, but intramammary catabolism of group 2 AA numerically increased (higher U:O). Anabolic effects of insulin on peripheral tissues in response to GG likely accounted for the reduced arterial concentrations of $\mathrm{BHB}$ and group $2 \mathrm{AA}$ and the reduced intramammary catabolism of group 2 AA to maintain milk protein synthesis at the LMP level.

\section{Lipogenic Infusion Did Not Affect Mammary AA Utilization}

Infusion of palm olein did not affect MPF or mammary net uptake of any AA group. This outcome agrees with the findings of Nichols et al. (2019a) in response to 28-d dietary supplementation with rumen-inert saturated fat. However, those authors did report a tendency for milk protein yield to increase $45 \mathrm{~g} / \mathrm{d}$ with fat supplementation, whereas in the current study milk protein yield was not affected by LG. Interestingly, Nichols et al. (2019a) report Ser as the only AA to be affected by fat feeding at the level of mammary uptake and clearance, which was also observed in the current study. Data characterizing mammary gland kinetics in response to fat supplementation are limited. Previous work suggested that feeding LCFA might improve mammary AA extraction efficiency, but this improvement could be counteracted by depressed MPF if intramammary energy requirements are reduced when short-chain FA and glucose are spared by reduced de novo FA synthesis (reviewed by DePeters and Cant, 1992). However, subsequent stimulation of lactose synthesis from spared glucose increases ATP utilization (Cant et al., 2003). According to the hypothesis that MPF is regulated to maintain intramammary energy balance, it follows that palm olein infusion did not affect MPF in the current study because it decreased de novo milk FA synthesis (Nichols et al., 2019b), did not decrease milk lactose yield, and did not affect arterial BHB concentration.

Insulin concentration was not affected by palm olein infusion, and thus the anabolic effects of insulin on peripheral tissues did not initiate partitioning of EAA toward extramammary tissues in response to LG, in contrast with the effect of glucose infusion and in line with our hypothesis. Therefore, a greater portion of circulating AA were available for mammary AA uptake during palm olein infusion, but greater AA uptake was not observed, and milk protein output was not affected. Plasma urea concentration tended to increase with LG at the LMP level and tended to decrease at the HMP level, but it was numerically higher on HMP-LG than on LMP-LG, which is consistent with greater AA catabolism as protein supply increases. In agreement with our hypothesis, although both energy substrates resulted in the same level of milk protein synthesis, glucose infusion resulted in a larger response at the mammary gland level compared with palm olein to sequester AA.

\section{Mammary Glucose and LCFA Balance}

The $192 \mathrm{~g} / \mathrm{d}$ increase in lactose yield stimulated by the HMP level did not coincide with increased mammary glucose uptake in response to EAA infusion. Furthermore, at the HMP level (except when glucose was infused), mammary glucose uptake was insufficient to cover estimated requirements for lactose and fat synthesis, assuming 1.05 and $0.31 \mathrm{~g}$ of glucose is required to synthesize $1 \mathrm{~g}$ of lactose and fat, respectively (Dijkstra et al., 1996). Reported estimates indicate that $100 \%$ of glucose in lactose but only 60 to $80 \%$ of galactose in lactose is derived from plasma glucose (Sunehag et al., 2002; Bequette et al., 2006). Amino acids can contribute to carbon substrates required for galactose synthesis by the gland, and this contribution could be affected by absorptive EAA level (Bequette et al., 2006; Maxin et al., 2013). Maxin et al. (2013) observed lower contribution of labeled glucose in milk galactose during abomasal AA infusion, indicating that a larger portion of nonglucose carbon (up to 50\%) was used for galactose synthesis in the mammary gland when AA were infused. Bequette et al. (2006) estimated that $12 \%$ of galactose synthesized by mammary cells in vitro was derived from EAA catabolism. In the current study, 
the $\mathrm{U}: \mathrm{O}$ of TAA was the furthest from unity at the HMP level. If a portion of AA extracted by the gland contributed to galactose synthesis, this would not be accounted for in our TAA balance or in our glucose balance but would reduce the apparent glucose deficit for lactose synthesis. In response to abomasal infusion of the same EAA profile and dose, the reported lactose yield expressed relative to reported mammary glucose uptake by Nichols et al. (2016) was 1.12, comparable with the values of 1.26 and 1.16 on HMP-C and HMPLG in the current study.

Palm olein infusion did not affect circulating glucose or net mammary glucose uptake but produced the same level of lactose yield as glucose infusion, independent of MP level. Absorption of LCFA into circulation promotes their direct incorporation into milk fat, thereby reducing de novo FA synthesis and glucose requirements for oxidative catabolism, which in turn may spare some intramammary glucose for lactose synthesis (Chilliard, 1993; Hammon et al., 2008). Mammary net uptake of TAG and LCFA $(\geq 16 \mathrm{C})$ increased in response to LG, and milk LCFA $(\geq 16 \mathrm{C})$ output increased (Nichols et al., 2019b). However, LCFA uptake equilibrated with LCFA output in milk only with HMP-LG infusion. A larger portion than the assumed $50 \%$ of $\mathrm{C} 16$ may have been synthesized de novo on the other treatments, which would mitigate some or all of the calculated shortfall in net mammary supply of LCFA from blood relative to milk LCFA. However, with the assumption of more $16 \mathrm{C}$ FA being synthesized de novo in the gland, intramammary glucose requirement would become increasingly deficient to support glycerol synthesis and yield NADPH. The concentration of FA $<16 \mathrm{C}$, assumed to be $100 \%$ synthesized de novo, decreased in milk fat with palm olein infusion (Nichols et al., 2019b), which would allow some glucose sparing. Increased mammary uptake of BHB at the HMP level could have resulted in more than $50 \%$ of $16 \mathrm{C} \mathrm{FA}$ synthesized de novo, which would partly offset the apparent deficit in LCFA balance at the HMP level.

\section{CONCLUSIONS}

Increased absorptive supply of glucose and palm olein differentially affected mammary gland metabolite utilization, irrespective of MP level. Anabolic effects of insulin on extramammary peripheral tissues during glucose infusion likely accounted for the reduced arterial concentrations of $\mathrm{BHB}$ and group $2 \mathrm{AA}$ and increased $\mathrm{MPF}$, regardless of MP level, and the reduced intramammary catabolism of group $2 \mathrm{AA}$ at the LMP level. We suspect glucose stimulated lipogenesis in adipose and increased MPF to maintain intramammary ATP balance. Regardless of protein level, palm olein did not promote an insulin response and did not affect arterial AA concentrations or mammary AA utilization. The HMP level increased milk protein yield, increased uptake of all EAA groups, and increased intramammary catabolism of group $2 \mathrm{AA}$ and BCAA, but it decreased that of NEAA. At the HMP level, mammary glucose uptake was insufficient to cover estimated requirements for lactose and fat synthesis, except when glucose was infused. This deficit may have been mitigated through shifts in intramammary metabolite partitioning, such as contribution of EAA carbon to galactose, and decreased de novo 16C FA synthesis. These results suggest that lactose secretion is not solely dependent on mammary glucose supply at high MP levels, and they illustrate the flexibility of mammary metabolite utilization.

\section{ACKNOWLEDGMENTS}

The authors gratefully acknowledge technical assistance from Sven Alferink, Marcel Heetkamp, Tamme Zandstra, and the animal caretakers of the experimental facilities of "Carus" (Wageningen University and Research, Wageningen, the Netherlands) and from Inge van Bakel and Koen van Helvoort (students of Wageningen University, Wageningen, the Netherlands). Ultra-performance liquid chromatography was performed by Colette Mustière and Sophie Lemosquet (INRA PEGASE, Saint-Gilles, France) with support from Ajinomoto Animal Nutrition Europe (Paris, France). This research was conducted by Wageningen University and Research (Wageningen Livestock Research, Wageningen, the Netherlands), commissioned and funded by the Ministry of Agriculture, Nature and Food Quality (The Hague, the Netherlands) within the framework of Policy Support Research theme "Feed4Foodure" (BO-31.03-005-001; TKI-AF12039B), and by the Vereniging Diervoederonderzoek Nederland (Rijswijk, the Netherlands).

\section{REFERENCES}

Arieli, A., S. Abramson, S. J. Mabjeesh, S. Zamwel, and I. Bruckental. 2001. Effect of site and source of energy supplementation on milk yield in dairy cows. J. Dairy Sci. 84:462-470.

Backwell, F. R. C., B. J. Bequette, D. Wilson, A. G. Calder, J. A. Metcalf, D. Wray-Cahen, J. C. MacRae, D. E. Beever, and G. Lobley. 1994. Utilization of dipeptides by the caprine mammary gland for milk protein synthesis. Am. J. Physiol. 267:R1-R6.

Bequette, B. J., F. R. C. Backwell, C. E. Kyle, A. G. Calder, V. Buchan, L. A. Crompton, J. France, and J. C. MacCrae. 1999. Vascular sources of phenylalanine, tyrosine, lysine, and methionine for casein synthesis in lactating goats. J. Dairy Sci. 82:362-377.

Bequette, B. J., C. E. Kyle, L. A. Crompton, V. Buchan, and M. D. Hanigan. 2001. Insulin regulates milk production and mammary gland and hind-leg amino acid fluxes and blood flow in lactating goats. J. Dairy Sci. 84:241-255.

Bequette, B. J., N. E. Sunny, S. W. El-Kadi, and S. L. Owens. 2006. Application of stable isotopes and mass isotopomer distribution 
analysis to the study of intermediary metabolism of nutrients. J. Anim. Sci. 84(Suppl.):E50-E59.

Boerman, J. P., S. B. Potts, M. J. VandeHaar, and A. L. Lock. 2015. Effects of partly replacing dietary starch with fiber and fat on milk production and energy partitioning. J. Dairy Sci. 98:7264-7276.

Brosnan, J. T., and M. E. Brosnan. 2006. Branched-chain amino acids: Enzyme and substrate regulation. J. Nutr. 136:207S-211S.

Cant, J. P., R. Berthiaume, H. Lapierre, P. H. Luimes, B. W. McBride, and D. Pacheco. 2003. Responses of the bovine mammary glands to absorptive supply of single amino acids. Can. J. Anim. Sci. 83:341-355.

Cant, J. P., E. J. DePeters, and R. L. Baldwin. 1993a. Mammary uptake of energy metabolites in dairy cows fed fat and its relationship to milk protein depression. J. Dairy Sci. 76:2254-2265.

Cant, J. P., E. J. DePeters, and R. L. Baldwin. 1993b. Mammary amino acid utilization in dairy cows fed fat and its relationship to milk protein depression. J. Dairy Sci. 76:762-774.

Casper, D. P., and D. J. Schingoethe. 1989. Model to describe and alleviate milk protein depression in early lactation dairy cows fed a high fat diet. J. Dairy Sci. 72:3327-3335.

Centraal Veevoederbureau (CVB). 2008. CVB Table Ruminants 2008, series nr. 43. CVB, the Hague, the Netherlands.

Chilliard, Y. 1993. Dietary fat and adipose tissue metabolism in ruminants, pigs, and rodents: A review. J. Dairy Sci. 76:3897-3931.

Crompton, L. A., J. France, C. K. Reynolds, J. A. N. Mills, M. D. Hanigan, J. L. Ellis, A. Bannink, B. J. Bequette, and J. Dijkstra. 2014. An isotope dilution model for partitioning phenylalanine and tyrosine uptake by the mammary gland of lactating dairy cows. J. Theor. Biol. 359:54-60.

Curtis, R. V., J. J. M. Kim, J. Doelman, and J. P. Cant. 2018. Maintenance of plasma branched-chain amino acid concentrations during glucose infusion directs essential amino acids to extra-mammary tissues in lactating dairy cows. J. Dairy Sci. 101:4542-4553.

DePeters, E. J., and J. P. Cant. 1992. Nutritional factors influencing the nitrogen composition of bovine milk: A review. J. Dairy Sci. 75:2043-2070.

DePeters, E. J., and J. D. Ferguson. 1992. Nonprotein nitrogen distribution in the milk of cows. J. Dairy Sci. 75:3192-3209.

Dijkstra, J., J. France, A. G. Assis, H. D. St. C. Neal, O. F. Campos, and L. M. J. Aroeira. 1996. Simulation of digestion in cattle fed sugarcane: Prediction of nutrient supply for milk production with locally available supplements. J. Agric. Sci. 127:247-260.

Doelman, J., R. V. Curtis, M. Carson, J. J. M. Kim, J. A. Metcalf, and J. P. Cant. 2015. Essential amino acid infusions stimulate mammary expression of eukaryotic initiation factor $2 \mathrm{~B} \varepsilon$ but milk protein yield is not increased during an imbalance. J. Dairy Sci. 98:4499-4508.

Doepel, L., and H. Lapierre. 2010. Changes in production and mammary metabolism of dairy cows in response to essential and nonessential amino acid infusions. J. Dairy Sci. 93:3264-3274.

Doepel, L., H. Lapierre, and J. J. Kennelly. 2002. Peripartum performance and metabolism of dairy cows in response to prepartum energy and protein intake. J. Dairy Sci. 85:2315-2334.

Emery, R. S., L. D. Brown, and J. W. Bell. 1965. Correlation of milk fat with dietary and metabolic factors in cows fed restricted-roughage rations supplemented with magnesium oxide or sodium bicarbonate. J. Dairy Sci. 48:1647-1651.

Guinard, J., and H. Rulquin. 1994. Effect of graded levels of duodenal infusions of casein on mammary uptake in lactating cows. 2. Individual amino acids. J. Dairy Sci. 77:3304-3315.

Hammon, H. M., C. C. Metges, P. Junghans, F. Becker, O. Bellmann, F. Schnieder, G. Nürnberg, P. Dubreuil, and H. Lapierre. 2008. Metabolic changes and net portal flux in dairy cows fed a ration containing rumen-protected fat as compared to a control diet. J. Dairy Sci. 91:208-217.

Hanigan, M. D., J. France, D. Wray-Cahen, D. E. Beever, G. E. Lobley, L. Reutzel, and N. E. Smith. 1998. Alternative models for analyses of liver and mammary transorgan metabolite extraction data. Br. J. Nutr. 79:63-78

Haque, M. N., J. Guinard-Flament, P. Lamberton, C. Mustière, and S. Lemosquet. 2015. Changes in mammary metabolism in response to the provision of an ideal amino acid profile at 2 levels of metabolizable protein supply in dairy cows: Consequences on efficiency. J. Dairy Sci. 98:3951-3968.

Haque, M. N., H. Rulquin, A. Andrade, P. Faverdin, J. L. Peyraud, and S. Lemosquet. 2012. Milk protein synthesis in response to the provision of an "ideal" amino acid profile at 2 levels of metabolizable protein supply in dairy cows. J. Dairy Sci. 95:5876-5887.

Huntington, G. B., D. L. Harmon, and C. J. Richards. 2006. Sites, rates, and limits of starch digestion and glucose metabolism in growing cattle. J. Anim. Sci. 84(Suppl.):E14-E24.

ISO. 2013. Milk and liquid milk products. Guidelines for the application of mid-infrared spectrometry. International Organization for Standardization (ISO), Geneva, Switzerland.

Jorgensen, G. N., and B. L. Larson. 1968. Conversion of phenylalanine to tyrosine in the bovine mammary secretory cell. Biochim. Biophys. Acta 165:121-126.

Lapierre, H., J. P. Blouin, J. F. Bernier, C. K. Reynolds, P. Dubreuil, and G. E. Lobley. 2002. Effect of supply of metabolizable protein on whole body and splanchnic leucine metabolism in lactating dairy cows. J. Dairy Sci. 85:2631-2641.

Lapierre, H., G. E. Lobley, L. Doepel, G. Raggio, H. Rulquin, and S. Lemosquet. 2012. Mammary metabolism of amino acids in dairy cows. J. Anim. Sci. 90:1708-1721.

Lemosquet, S., G. E. Lobley, R. Koopman, L. J. C. van Loon, A. K. Kies, and H. Lapierre. 2010. A large supply of phenylalanine is not oxidised by the mammary gland of dairy cows. Pages 137-138 in EAAP Publication No. 127. G. Matteo Crovetto, ed. Wageningen Academic Publishers, Wageningen, the Netherlands.

Lemosquet, S., G. Raggio, G. E. Lobley, H. Rulquin, J. Guinard-Flament, and H. Lapierre. 2009. Whole-body glucose metabolism and mammary energetic nutrient metabolism in lactating dairy cows receiving digestive infusions of casein and propionic acid. J. Dairy Sci. 92:6068-6082.

Lobley, G. E. 1998. Nutritional and hormonal control of muscle and peripheral tissue metabolism in farm species. Livest. Prod. Sci 56:91-114.

Mackle, T. R., D. A. Dwyer, K. L. Ingvartsen, P. Y. Chouinard, J. M. Lynch, D. M. Barbano, and D. E. Bauman. 1999. Effect of insulin and amino acids on milk protein concentration and yield from dairy cows. J. Dairy Sci. 82:1512-1524.

Mackle, T. R., D. A. Dwyer, K. L. Ingvartsen, P. Y. Chouinard, D. A Ross, and D. E. Bauman. 2000. Effects of insulin and postruminal supply of protein on use of amino acids by the mammary gland for milk protein synthesis. J. Dairy Sci. 83:93-105.

Maxin, G., D. R. Ouellet, and H. Lapierre. 2013. Contribution of amino acids to glucose and lactose synthesis in lactating dairy cows. Pages 443-444 in Energy and Protein Metabolism and Nutrition in Sustainable Animal Production. Energy and Protein Metabolism and Nutrition in Sustainable Animal Production. Vol. 134. J. W. Oltjen, E. Kebreab, and H. Lapierre, eds. Wageningen Academic Publishers, the Netherlands.

Mepham, T. B. 1987. Physiology of Lactation. Open University Press, Milton Keynes, UK.

Metcalf, J. A., L. A. Crompton, D. Wray-Cahen, M. A. Lomax, J. D. Sutton, D. E. Beever, J. C. MacRae, B. J. Bequette, F. R. C. Backwell, and G. E. Lobley. 1996. Responses in milk constituents to intravascular administration of two mixtures of amino acids to dairy cows. J. Dairy Sci. 79:1425-1429.

Nichols, K., J. Dijkstra, H. van Laar, S. Pacheco, H. J. van Valenberg, and A. Bannink. 2019b. Energy and nitrogen partitioning in dairy cows at low or high metabolizable protein levels is affected differently by postrumen glucogenic and lipogenic substrates. J. Dairy Sci. 102:395-412.

Nichols, K., J. J. M. Kim, M. Carson, J. A. Metcalf, J. P. Cant, and J. Doelman. 2016. Glucose supplementation stimulates peripheral branched-chain amino acid catabolism in lactating dairy cows during essential amino acid infusions. J. Dairy Sci. 99:1145-1160.

Nichols, K., H. van Laar, A. Bannink, and J. Dijkstra. 2019a. Mammary gland utilization of amino acids and energy metabolites differs when dairy cow rations are isoenergetically supplemented with protein and fat. J. Dairy Sci. 102:1160-1175. 
Ørskov, E. R., D. E. Meehan, N. A. MacLeod, and D. J. Kyle. 1999. Effect of glucose supply on fasting nitrogen excretion and effect of level and type of volatile fatty acid infusion on response to protein infusion in cattle. Br. J. Nutr. 81:389-393.

Raggio, G., S. Lemosquet, G. E. Lobley, H. Rulquin, and H. Lapierre. 2006b. Effect of casein and propionate supply on mammary protein metabolism in lactating dairy cows. J. Dairy Sci. 89:4340-4351.

Raggio, G., G. E. Lobley, S. Lemosquet, H. Rulquin, and H. Lapierre. 2006a. Effect of casein and propionate supply on whole body protein metabolism in lactating dairy cows. Can. J. Anim. Sci. 86:81-89.

Rigout, S., S. Lemosquet, A. Bach, J. W. Blum, and H. Rulquin. 2002. Duodenal infusion of glucose decreases milk fat production in grass silage-fed dairy cows. J. Dairy Sci. 85:2541-2550.

Rius, A. G., J. A. D. R. N. Appuhamy, J. Cyriac, D. Kirovski, O. Becvar, J. Escobar, M. L. McGilliard, B. J. Bequette, R. M. Akers, and M. D. Hanigan. 2010. Regulation of protein synthesis in mammary glands of lactating dairy cows by starch and amino acids. J. Dairy Sci. 93:3114-3127.

Rulquin, H., S. Rigout, S. Lemosquet, and A. Bach. 2004. Infusion of glucose directs circulating amino acids to the mammary gland in well-fed dairy cows. J. Dairy Sci. 87:340-349.

Sunehag, A. L., K. Louie, J. L. Bier, S. Tigas, and M. W. Haymond. 2002. Hexoneogenesis in the human breast during lactation. J. Clin. Endocrinol. Metab. 87:297-301. van Gastelen, S., E. C. Antunes-Fernandes, K. A. Hettinga, G. Klop, S. J. J. Alferink, W. H. Hendriks, and J. Dijkstra. 2015. Enteric methane production, rumen volatile fatty acid concentrations, and milk fatty acid composition in lactating Holstein-Friesian cows fed grass silage- or corn silage-based diets. J. Dairy Sci. 98:1915-1927. van Hoeij, R. J., J. Dijkstra, R. M. Bruckmaier, J. J. Gross, T. J. G. M. Lam, G. J. Remmelink, B. Kemp, and A. T. M. van Knegsel. 2017. Consequences of dietary energy source and energy level on energy balance, lactogenic hormones, and lactation curve characteristics of cows after a short or omitted dry period. J. Dairy Sci. 100:8544-8564.

van Knegsel, A. T. M., H. van den Brand, J. Dijkstra, W. M. van Straalen, R. Jorritsma, S. Tamminga, and B. Kemp. 2007. Effect of glucogenic vs. lipogenic diets on energy balance, blood metabolites, and reproduction in primiparous and multiparous dairy cows in early lactation. J. Dairy Sci. 90:3397-3409.

Verbeke, R., E. Roets, A. Massart-Leën, and G. Peeters. 1972. Metabolism of $\left[\mathrm{U}_{-}{ }^{14} \mathrm{C}\right]$-L-threonine and $\left[\mathrm{U}_{-}{ }^{14} \mathrm{C}\right]$-L-phenylalanine by the isolated perfused udder. J. Dairy Res. 39:239-250.

Vernon, R. G., E. Finley, and E. Taylor. 1985. Fatty acid synthesis from amino acids in sheep adipose tissue. Comp. Biochem. Physiol. B 82:133-136. 